\title{
TRABALHADORES, DIREITO À SAÚDE E ORDEM SOCIAL NO BRASIL
}

Eduardo Navarro Stotz

\begin{abstract}
Resumo: O ensaio considera a política de saúde parte essencial do processo de legitimação da ordem social burguesa democrática. Examina a formulação dessa política no processo de redemocratização política e aponta o problema da segmentação social das clientelas do sistema de saúde instituído. Assinala a solidariedade social entre os trabalhadores como condição para a superação do problema da eqüidade na saúde.

Palavras-chave: política social; legitimação; solidariedade social.

Abstract: This essay argues that health policy is an essential legitimizing factor with regard to the bourgeois democratic social order. It examines how policy is formulated within the political re-democratization process and considers the social segmentation of the clients of the existing health care system. It highlights the importance of worker solidarity in overcoming inequities in health care.

Key words: social policy; legitimization; social solidarity.
\end{abstract}

$\mathrm{N}$ o início dos anos 80, em encontro com Mário Pedrosa, um intelectual de esquerda de grande prestígio no país e no mundo, um grupo de amigos conversava sobre as novas perspectivas que se abriam com as grandes mobilizações operárias. $\mathrm{O}$ regime militar estava em franco processo de decomposição. A uma certa altura da conversa, um tom sombrio perpassou a avaliação de Mário Pedrosa sobre as previsões. "As nossas classes dominantes" - advertiu - "nunca fizeram concessões realmente importantes para as classes dominadas. E sabem por que? Porque as lutas sociais nunca redundaram em vitórias significativas, pois via de regra foram escamoteadas ou perdidas com golpes de Estado e implantação de regimes autoritários."

Hoje, passados tantos anos, Mário já faleceu e vivemos sob um regime formalmente democrático; parece que algumas concessões foram realmente feitas depois de tantas lutas. Será mesmo?

O problema apontado por Mário Pedrosa, no início dos anos 80 , remete à questão da dominação consensual de classes no Brasil, ou seja, a hegemonia. A construção do consenso, na medida em que pressupõe melhorias na posição relativa de alguns segmentos das classes domina- das, traz como proposição implícita a máxima dividir para reinar. As políticas sociais implementadas pelo Estado podem ser entendidas como mecanismos destinados a transferir rendas - via benefícios - entre diferentes grupos sociais, sendo que sua função essencial é resolver a questão da redistribuição da riqueza nos termos da manutenção da ordem burguesa.

Não é mais desta forma e perspectiva analítica que as ciências sociais tratam do tema das políticas sociais atualmente. A abordagem da hegemonia ou dominação consensual foi, ao longo do processo de redemocratização política do Brasil, abandonada e, com isso, a legitimação da ordem deixou de conferir sentido ao estudo das políticas sociais no Brasil. $\mathrm{O}$ tratamento dado ao tema das políticas sociais na literatura brasileira recente tendeu a se deslocar na mesma direção imposta pela mudança do regime político, isto é, da expectativa da "cidadanização" das classes trabalhadoras (Fleury, 1994). Buscou-se orientar a pesquisa e a reflexão de acordo com um modelo interpretativo baseado na experiência dos Estados de Bem-Estar Social do capitalismo avançado (Aureliano e Draibe, 1989).

De acordo com Liana Aureliano e Sonia Draibe (1989), a intervenção social do Estado fortaleceu, a partir de 1964, 
um desenvolvimento econômico conservador e socialmente excludente. As autoras indicam as características do sistema de proteção social brasileiro: extrema centralização política e financeira no nível federal das ações sociais do Governo; uma formidável fragmentação institucional; exclusão da participação social e política da população nos processos de decisão; princípio do autofinanciamento do investimento social; e princípio da privatização. Quando examinam a política social da Nova República, as autoras assinalam como, no discurso oficial, pretendeu-se a superação do assistencialismo e da forma tutelar de proteção, em prol de uma concepção calcada nos direitos sociais de cidadania. Porém, no tocante às condições de efetivação do discurso, o padrão de proteção social do Estado autoritário não foi alterado em seus pilares básicos, financeiros e organizacionais.

Entretanto, a política de saúde seria uma exceção, demonstrando a possibilidade de outro rumo do campo da proteção social. De fato, a descentralização, a participação popular, o financiamento público e o acesso com base no princípio do direito, características do sistema de saúde mais marcantes a partir de 1991, parecem reverter a tendência dominante nas políticas sociais, apontada pelas autoras. Um estudo histórico das lutas sociais no processo de redemocratização permitiria, contudo, examinar inclusive os mesmos aspectos sob uma outra ótica que não aquela restrita à análise setorial, no plano de uma política social específica, dos avanços (ou retrocessos) de certos princípios. Não é irrelevante - antes o contrário - que o Conselho Nacional de Saúde (CNS) tenha recentemente elaborado um documento para ser entregue aos candidatos à Presidência da República, no qual se cobra o compromisso com o investimento público na oferta de serviços. Trata-se de um desafio que, nas palavras do documento, põe em questão a eqüidade na saúde (CNS, 2002). Desafio que traduz, a nosso ver, a questão da legitimação da ordem burguesa democrática.

\section{A APREENSÃO DE CONCEITOS DE UM CORPO TEÓRICO NÃO É ESPONTÂNEA E NEM FRUTO DO PENSAMENTO ISOLADO}

A reforma sanitária - processo que será examinado na seção seguinte do texto - pode ser vista como uma reforma setorial no contexto de um processo de redemocratização política que mobilizou quase toda a sociedade brasileira ao longo de mais de uma década. A apreensão intelectual deste processo teve como eixo interpretativo a concepção sobre as relações entre sociedade civil e Estado, de Antonio Gramsci, tal como formulada nas duas publicações brasileiras mais significativas de sua vasta porém fragmentada obra, os assim denominados Cadernos do Cárcere. ${ }^{1}$

Pode-se dizer que o referencial gramsciano constitui o patrimônio comum das esquerdas na época da redemocratização política. Um dos núcleos de pesquisa organizados na área da saúde, em meados dos anos 80, fez uma apropriação singular do pensador e militante comunista italiano. A "leitura" realizada por esses pesquisadores partia da preocupação com a dimensão educativa e cognitiva em jogo nas relações entre pesquisadores, técnicos e profissionais de saúde e movimentos sociais, nas quais, pela mediação dos serviços públicos, se construía um conhecimento implícito das possibilidades e limites da ação dos interesses sociais. Os valores, crenças e noções a respeito de direitos e deveres dos distintos sujeitos, alvos de todo um processo de interpretação que conferia ao aprendizado e à socialização um caráter muitas vezes ambíguo e/ou contraditório, foram especialmente destacados no relatório final da pesquisa realizada pelo núcleo (Valla, 1988).

Dentre os aspectos da apropriação dos textos gramscianos, ressalta-se em particular o entendimento de que, sob o capitalismo programático, há uma interpenetração entre as duas esferas. Segundo o relatório: "Se a sociedade civil compreende o conjunto de organismos que correspondem à função de hegemonia que a burguesia exerce em toda a sociedade, inserimos nesse conceito tanto as associações de moradores em favelas, como os órgãos do Estado, nos diversos níveis e atribuições. Trata-se de uma noção ampliada da sociedade civil. Marx compreendeu-a, na Ideologia Alemã, como a expressão das relações sociais entre os homens na produção de sua vida. Gramsci ampliou esta concepção para abranger a superestrutura ideológica, isto é, a organização através da qual a classe dominante difunde a sua ideologia (organização escolar, imprensa, fração cultural da magistratura e do oficialato das Forças Armadas, assim como a Igreja)".

Deve-se abrir aqui um breve parêntesis. A importância de Antonio Gramsci, no Brasil, é contemporânea aos primeiros sinais da crise do regime militar. Em 1977, no IV Congresso das Classes Produtoras, ao lado de uma posição favorável à desestatização da economia, vários representantes do que se convencionou a chamar de burguesia nacional manifestaram a defesa do retorno à democracia. Neste mesmo ano, as manifestações de massa dos estudan- 
tes no Rio de Janeiro e em São Paulo ampliaram o descontentamento social com as limitações do regime em expressar interesses divergentes. No ano seguinte, entravam em cena os operários com uma onda de greves a partir das fábricas: "O problema da legitimidade começou a tomar forma mais nítida na sociedade e a intelectualidade 'redescobre' Gramsci. Sua concepção sobre o Estado, ainda que referida à dominação de classe, permitia pensar a nova problemática, assim como informa uma nova prática dos intelectuais que compunham o Estado. A rede pública de saúde, ensino e demais entidades estatais voltadas para as políticas sociais deixaram de ser vistas como espaços exclusivos de controle e coerção. A leitura 'gramsciana' permitia pensá-los como verdadeiras 'trincheiras', dentro de uma longa 'guerra de posições' para a conquista de hegemonia da sociedade. Contudo, o longo processo de decomposição do regime militar - apresentado oficialmente como institucionalização, na forma geiselista e golberiana de abertura lenta e gradual - marcou-se também por certas particularidades, dando lugar a uma clivagem de fileiras no movimento de oposição. A conquista de posições no interior do aparelho de Estado, dentro de uma concepção crescentemente instrumental, distanciou-se, cada vez mais, da resistência cristalizada por uma concepção de autonomia do movimento popular" (Valla, 1988).

Neste contexto, qual era a leitura de Gramsci feita pelos intelectuais da área da saúde? A leitura passava por Giovanni Berlinguer, que propunha a conquista de posições do Estado por meio de avanço do movimento popular (Oliveira, 1989). O relatório do núcleo de pesquisa contém, a esse respeito, uma advertência: "a falta de um forte respaldo no movimento popular que, diga-se de passagem, não adquiriu ainda suficiente vigor e estruturação no setor de saúde coloca o risco permanente de a conquista da hegemonia transformar-se em processo de cooptação".

Entretanto, em que pese o entendimento de que o processo de democratização do Estado implicava o reforço do papel da sociedade civil por meio de participação das classes trabalhadoras representadas por seus órgãos representativos - chamados a participar de estruturas criadas pelo Estado, de modo a obter um mínimo de consenso e, assim, legitimar a direção política que a classe dirigente pretendia imprimir ao conjunto da sociedade -, não estava ainda claro, para a intelectualidade acadêmica na área da saúde, que o segmento mais organizado dessas classes - o operariado do "setor moderno" - estava, apesar da posição oficial de sua representação sindical nacional, auto-excluindo-se da participação no futuro sistema úni- co de saúde. Tratava-se, em certa medida, do resultado de negociações diretas entre os sindicatos de trabalhadores da indústria e o patronato, no qual o atendimento pela "medicina de grupo" aparecia como uma vantagem diante das dificuldades de acesso dos serviços de saúde oferecidos pelo Inamps.

Uma nova compreensão das relações entre estratificação social e papel das políticas sociais (Brunhoff, 1985)² foi proposta, pioneiramente, por Regis de Castro Andrade, que desafiou o consenso acadêmico ao formular a idéia de que as modernas ditaduras requeriam mecanismos de legitimação próprios, distintos daqueles das democracias parlamentares. Cometeu, inclusive, o "sacrilégio" de basear-se nas idéias de Gramsci.

No caso brasileiro, a ditadura militar teria construído, por meio de políticas sociais, uma normatividade reguladora das relações de classe entre capital e trabalho, evitando as conseqüências desorganizadoras do desenvolvimento capitalista selvagem no Brasil (Andrade, 1982). O autor assinala que a tecnocracia privilegiava o recurso às políticas públicas para integrar as massas de trabalhadores "com carteira", deixando os mecanismos de mercado operarem no que dizia respeito ao operariado das indústrias modernas. As transferências de renda se faziam por intermédio de fundos previdenciários, de modo que este último setor, que contribuía mais, favorecia o primeiro e permitia inclusive a extensão de benefícios para o terceiro segmento, como as empregadas domésticas e os trabalhadores rurais. ${ }^{3}$ Do ponto de vista dos beneficiários da política social, o autor distingue três estratos: o operariado do setor moderno; a massa dos assalariados "com carteira"; e a massa dos trabalhadores urbanos e rurais do setor "informal". Esta avaliação da estratificação social supunha uma tendência ao assalariamento, concomitante com o desenvolvimento industrial e a urbanização.

\section{A REDEMOCRATIZAÇÃO E O "RESGATE DA DÍVIDA SOCIAL": UMA AVALIAÇÃO DA REFORMA SANITÁRIA}

As eleições municipais de 1972 consagraram o Movimento Democrático Brasileiro - MDB - oposição legal ao regime militar - em 31\% das 100 maiores cidades. Em 1976 , este percentual passou para 59\% e, em 1982, para $83 \%$. Nesse último ano, ocorreram as eleições diretas para os governos estaduais, com a vitória das oposições (Partido do Movimento Democrático Brasileiro - PMDB ) em São Paulo, Minas Gerais e Rio de Janeiro. 
Os resultados eleitorais e os novos arranjos políticoinstitucionais que daí decorreram foram expressão de um enorme movimento de massas que tomou conta do Brasil a partir de 1977, inicialmente um movimento de estudantes, representativo das classes médias, e depois movimentos do proletariado, numa onda de greves inédita na nossa história.

O fim do regime militar, antecipado por aqueles resultados políticos, aconteceu apenas em 1984, quando - em conseqüência da campanha das "diretas-já" - milhões de pessoas foram às ruas nas principais cidades do país. A emenda parlamentar das eleições diretas para a Presidência da República foi uma "pedra cantada", pois, nas regras do jogo anteriormente impostas pelos militares, eram necessários $2 / 3$ dos votos do Congresso para modificar a Constituição, algo inviável diante da composição parlamentar dominante. A solução seguida foi a da eleição indireta, por meio de Colégio Eleitoral. O candidato dos militares não foi apoiado pela maioria governista que, por sua vez, deu origem a uma cisão partidária. Um grupo de parlamentares liderado por Antonio Carlos Magalhães, José Sarney e Aureliano Chaves deixou então o partido governista (PDS) e criou o Partido da Frente Liberal (PFL). Este partido estabeleceu uma aliança com o PMDB, constituindo a Aliança Democrática, o que tornou possível a eleição indireta de Tancredo Neves, um político "moderado" do MDB, e de José Sarney, egresso do PDS.

Nos anos seguintes, os movimentos populares participaram de fóruns institucionais, articularam-se politicamente para influir na redefinição da ordem jurídica que consolidaria a ordem democrática (Assembléia Constituinte) e apoiaram candidaturas em eleições proporcionais. $\mathrm{Na}$ área da saúde, atores institucionais representaram esses movimentos, dando-lhe voz e projeto, no processo conhecido como reforma sanitária.

É importante observar que a redemocratização política trazia como pressuposto o chamado "resgate da dívida social" legada pelo regime militar. A esperança de uma redistribuição da renda fazia parte dos cálculos do processo democrático em marcha no período. É importante assinalar também que, no começo dos anos 80 , os tecnocratas da equipe econômica sob comando de Delfim Neto preferiram evitar a adoção integral de políticas de austeridade, tal como propostas pelo Fundo Monetário Internacional. A elevação das taxas de juros, os cortes nos gastos públicos, a abertura da economia e a flexibilidade cambial que faziam parte do receituário do FMI poderiam, se colocados em prática, comprometer a transição política.
Porém, quando se consideram, do ponto de vista distributivo, os precários resultados obtidos pela política social implementada ao longo dos anos 80 e 90, avulta-se a importância da reforma sanitária.

A institucionalização desse processo de reforma da política de saúde começou em 1981, com a participação de sanitaristas no corpo técnico do Conselho Consultivo de Saúde Previdenciária. Nesse momento, surgiu uma proposta de reorganização do sistema de saúde de cunho privatizante, que previa a organização de um setor privado autônomo capaz de atingir 78 milhões de pessoas, das quais 70 milhões estariam vinculadas à modalidade do tipo "convênio-empresa". Os 40\% restantes seriam cobertos pelo setor público.

A derrota dessa proposta manifestava o enfraquecimento dos interesses privados no processo institucional, mas correspondia também à situação econômico-social da época. Entre 1981 e 1983, o Brasil atravessou uma forte recessão econômica e o investimento público e privado caiu drasticamente, mantendo-se baixo durante toda a década de 80. O impacto dessa situação desorganizou um movimento que tinha levado à ação direta milhões de trabalhadores. Por outro lado, essa mesma situação tornava inviável, naquele momento, canalizar, para um sistema privado, parcelas significativas da população trabalhadora.

A partir de 1984, com a recuperação da economia, o movimento sindical retomou impulso. Porém, o mecanismo inflacionário em que se baseou o crescimento econômico e o estabelecimento de pisos salariais por categoria enfraqueceram o movimento sindical. Teve início uma lenta, mas progressiva, divisão interna no movimento sindical, processo que levou as lideranças a um horizonte de negociações cada vez mais limitado às categorias profissionais. Sua posição passou a ser a de negociar a saúde nos acordos coletivos de trabalho, voltando as costas ao sistema público então (em parte ainda hoje) marcado por graves deficiências em termos de acesso e qualidade. O movimento sindical refluiu politicamente, abandonou a arena política, saiu das ruas e deslocou-se para o interior das instituições do Estado.

Durante a década de 80 , outros atores entraram em cena, como os movimentos sociais urbanos, movimentos ecológicos, de mulheres, de negros, de portadores de deficiências, de parentes e amigos das vítimas de trânsito, de familiares de doentes mentais e de aposentados.

Uma análise sociológica da reforma sanitária neste período deixa patente que os profissionais e técnicos da saúde, os professores universitários, enfim, um segmento 
das classes médias urbanas, posicionaram-se como portavozes dos anseios das camadas mais pobres da população trabalhadora perante o aparelho de Estado encarregado da provisão dos serviços públicos. ${ }^{4}$

A organização do "movimento sanitário" começou por volta de $1976,{ }^{5}$ como um dos desdobramentos da vitória eleitoral do MDB, do qual participou grande número de profissionais e técnicos da área da saúde vinculados ao Partido Comunista Brasileiro. Entidades civis como o Cebes e a Abrasco tinham, segundo Sonia Fleury (1977), uma influência "institucionalista" mais forte, em detrimento de experiências voltadas para a redemocratização "por baixo". De acordo com a autora, a perspectiva da aglutinação das tendências renovadoras do setor saúde, em nível profissional, era uma manifestação da política de frente democrática ampla que estava na origem da sua liderança.

A outra perspectiva, mais identificada com o Partido dos Trabalhadores e as Comunidades Eclesiais de Base, estaria localizada em experiências de participação popu$\operatorname{lar}^{6}$ que, aliás, tiveram um peso muito grande nos anos 70 e 80. Pode-se lembrar aqui, entre outros, dos movimentos populares da Zona Leste, na cidade de São Paulo, do Movimento Popular de Saúde (Mops), organizado principalmente no interior do Brasil, e do Movimento de Reintegração dos Hansenianos (Morhan).

Apesar das clivagens apontadas, no movimento da reforma sanitária estava presente, de acordo com Fleury (1997:26), um ideário comum, ${ }^{7}$ pautado nas seguintes dimensões: "a construção de um novo saber que evidenciasse as relações entre saúde e estrutura social; a ampliação da consciência sanitária onde a Revista Saúde em Debate foi, e continua sendo, seu veículo privilegiado; a organização do movimento social, definindo espaços e estratégias de ação política".

A estratégia adotada pelos atores institucionais do movimento pela reforma sanitária foi basicamente a de propor e encaminhar a unificação das instituições estatais encarregadas da saúde da população e descentralizar as ações para os níveis subnacionais, em especial para os municípios. A unificação implicava superar a medicina previdenciária, organizada para os trabalhadores do mercado formal de trabalho pelo Instituto Nacional de Assistência Médica e Social, vinculado ao Ministério da Previdência.

O período entre 1982 e 1987 foi marcado pelos conflitos de implementação dessa estratégia, cuja superação somente aconteceu com a unificação de todo o setor esta- tal no Ministério da Saúde e a extinção do Inamps. Isso ocorreu a partir de 1986, com a VIII Conferência Nacional de Saúde, com cerca de 3.000 participantes e 1.000 delegados votantes. Os princípios defendidos na resolução final da Conferência foram depois consagrados na Constituição de 1988, sob o lema Saúde direito de todos, dever do Estado.

A institucionalização do SUS começou a tomar corpo nos anos 90, como resultado dos interesses criados com a estratégia da unificação descentralizada do sistema de saúde ao longo da década anterior; mais concretamente, os interesses políticos dos secretários municipais de saúde que se organizaram em Conselho Nacional, em 1987. O Conasems tornou-se um ator institucional de peso na implementação da reforma sanitária porque, pelas origens, ideologia e posição política, seus participantes identificavam-se com o movimento sanitarista dos anos 70 e 80 .

Contudo, o movimento da reforma sanitária deparouse com uma mudança radical de cenário e de perspectivas para a política pública nos anos 90. Com a eleição de Fernando Collor de Mello, o país entrou na "era neoliberal". O principal problema vivenciado nessa década, do ponto de vista da institucionalização do SUS, foi o do financiamento público.

Enquanto no período compreendido entre 1987 e 1994 o gasto público total como percentual do PIB diminuiu, nos anos subseqüentes ao Plano Real o problema passou a ser o da contenção do déficit público, em razão dos acordos assinados pelo governo de Fernando Henrique Cardoso com o Fundo Monetário Internacional. É por isso que, apesar da lenta recuperação dos valores, o orçamento executado tem sempre ficado abaixo do aprovado (Lobato, 2000).

À seletividade imposta pelos mecanismos de financiamento, com o recurso ao "surrado método do racionamento" (Vianna, 1998:142), agregou-se, pela percepção das dificuldades de acesso e baixa qualidade dos serviços, a "auto-exclusão" das classes médias e de importantes segmentos dos trabalhadores urbanos. Assim, o sistema acabou desembocando numa espécie de "universalização excludente" (Favaret e Oliveira, 1989).

Nesse aspecto é importante questionar o suposto de que o problema possa estar, no que diz respeito aos trabalhadores, nas limitações da estrutura de articulação de interesses (Vianna, 1998). A negociação direta entre patrões e empregados, depois de 1984, que substituiu a intervenção repressiva do Estado, somente pode ser vista como um obstáculo à ação coletiva de caráter público, porque, 
ao mesmo tempo em que e a quantidade e a qualidade dos serviços eram bastante precárias, tentativas de estabelecer alianças em torno de objetivos mais amplos tinham fracassado. E onde fracassaram? Principalmente no Estado de São Paulo, onde uma nova relação entre sindicatos e rede pública de serviços, a exemplo dos metalúrgicos de Santos e químicos do ABC, estava em organização na segunda metade da década de 80 (Stotz e Cruz Neto, 1989).

Deve-se ressaltar, porém, que a auto-exclusão dos trabalhadores urbanos com maior capacidade de organização nunca chegou a ser completa. $\mathrm{Na}$ verdade, a tendência à universalização do acesso ao sistema público de saúde sempre esteve em jogo, principalmente por causa do grau da concentração de renda vigente no país e das características restritivas do setor médico privado em termos de oferta, cobertura e preços dos seguros. O problema tem sido a forma como o acesso acontece. As relações entre os dois setores, - o privado e o público - são marcadas tanto por um padrão de acesso universal quanto por uma apropriação clientelística e privada do público. ${ }^{8}$

O sistema apresenta uma tendência à universalização, marcado, porém, por fortes contradições. O Sistema Único de Saúde, instituído pela Constituição brasileira de 1988, volta-se, de fato, para a maioria da população. Contudo, ao lado desse sistema existe uma ampla clientela do setor privado autônomo, estimada em 29 milhões de usuários (IBGE, 1998). O crescimento desse setor foi ainda maior nos últimos anos. A denominação sistema único de saúde é, portanto, uma contradição em termos. O correto seria chamá-lo de sistema público de saúde.

É em torno das dificuldades de acesso universal ao sistema de saúde ${ }^{9}$ e do problema da segmentação social das clientelas que se desenrolam os capítulos do processo de legitimação da ordem burguesa no Brasil. Os articuladores do movimento sanitário, em suas diferentes vertentes, sempre tiveram essa percepção. A dimensão do déficit de cobertura da população e uma avaliação política da necessidade de expandir a oferta de serviços públicos de saúde levaram os planejadores, no Ministério da Saúde, à formulação do Programa de Saúde da Família (PSF). O programa, instituído em 1994 como uma estratégia de reorientação do modelo assistencial, teve sua implementação em todo o país apenas a partir de 1998, em decorrência dos estímulos financeiros de que passou a dispor. Apresentado como uma estratégia de reorientação do modelo assistencial, deve ser avaliado inicialmente como um programa de extensão da cobertura, centrado em ações básicas de saúde. ${ }^{10}$
A percepção desse programa como uma possível resposta às imposições de ordem macroeconômicas decorrentes dos acordos com o FMI fica sugerida no artigo de Maria Ceci Misoczky (1995:6-7). A autora aponta para a relação entre o pacote mínimo essencial de saúde pública e de serviços clínicos proposto pelo Banco Mundial (1993) e o modelo de atenção à saúde que é uma espécie de reedição da medicina pobre para pobres baseada na Atenção Primária da Saúde: “Também não é difícil associar este modelo de atenção com o modelo da medicina de família/comunitária. É evidente que, para oferecer o pacote mínimo essencial, médicos especialistas, mesmo nas especialidades básicas, são desnecessários, assim como investimentos na qualificação e modernização da rede de serviços. Nesta perspectiva, fazem sentido as menções do Presidente FHC sobre a possibilidade de melhorar a saúde sem aumentar o orçamento do SUS".

Qualquer sistema de saúde deve funcionar de modo a compensar, no plano individual, problemas cuja determinação ou condicionamento devem ser atribuídos às relações sociais opressivas e à falta de proteção social diante delas. ${ }^{11}$ Fracassos ou limitações em cumprir esse papel constituem em si fatores de des-legitimação da ordem social. Então, como se deve analisar, à luz dessa problemática, o movimento reformista na saúde?

Um olhar retrospectivo (Escorel, 1998) aponta para as limitações de uma escolha estratégica. A autora afirma que os articuladores do movimento sanitarista priorizaram a ocupação dos "espaços públicos”, separando-se do movimento popular de origem. Passaram, em decorrência, a sofrer as limitações das alianças impostas pelas instituições públicas de saúde, ora transformadas em locus de contra-hegemonia. Na verdade, o argumento a favor da contra-hegemonia somente teria plausibilidade, na perspectiva gramsciana de "guerra de posições", se amparado numa ampla e forte aliança entre profissionais e técnicos do setor público e os potenciais beneficiários desse setor: os trabalhadores da cidade e do campo. Isso não aconteceu.

\section{O MUNDO DO TRABALHO: DESAFIOS E PERSPECTIVAS}

Entretanto, cabe indagar, diante da constatação de uma retração profunda do movimento operário e das manifestações dos trabalhadores em geral, se ainda tem sentido falar de políticas sociais e legitimação da ordem com referência ao mundo do trabalho. 
Há um consenso entre os analistas de que o movimento operário-sindical está vivendo, em todo o mundo, uma profunda crise de identidade em virtude da ampliação da insegurança do e no trabalho provocada pela ofensiva internacional do "capital reestruturado" (Mattoso, 1994). Fazem parte dessa ofensiva a "flexibilização" dos direitos sociais, a terceirização das atividades, o desemprego e o subemprego que se traduzem em decréscimo no número de associados, perda de prestígio e esvaziamento do papel dos sindicatos, com dificuldade maior de articular a vontade coletiva dos trabalhadores em suas respectivas bases. ${ }^{12}$

A ação dos trabalhadores refluiu das formas mais centralizadas de luta para o microcenário das empresas. Porém, uma vez chegada a este nível, atingiu o que Victor Meyer (2001) denominou de "núcleo duro" da resistência dos trabalhadores.

Essa situação tem suscitado um questionamento quanto à centralidade da categoria trabalho para definir padrões de sociabilidade e de funcionamento da ordem social inclusivas sob o sistema capitalista (Offe, 1994). A diversidade e heterogeneidade das condições que se apresentam no mundo do trabalho aparecem como base empírica para sustentar essa argumentação.

Navarro (1993) contesta tal perspectiva analítica da Sociologia (e também dos economistas "regulacionistas") ao chamar atenção para o dado histórico da heterogeneidade estrutural das relações e condições de trabalho sob o capitalismo desde os seus primórdios. A classe trabalhadora sempre esteve estratificada por diversas categorias, a exemplo das profissões, dos grupos étnicos e do gênero. Para constatar a diversidade que marca estruturalmente a classe operária, basta lembrar as páginas que Marx consagra, em $O$ Capital, à acumulação de capital e à criação de uma superpopulação operária relativa.

Por outro lado, a "solidariedade de classe" depende de uma atuação política que procure preservar ou conquistar direitos sociais para o conjunto dos trabalhadores. Reformas gerais baseadas na redistribuição de recursos entre o capital e o trabalho - e não entre os trabalhadores com base em fundos sociais - estimulam a unidade e contribuem para superar a fragmentação imposta pelas formas do desenvolvimento atual do capitalista.

Inscritas nesse horizonte, as lutas dos trabalhadores europeus contra as tentativas de reforma neoliberal no âmbito do Estado de Bem-Estar produziram alguns eventos de grande magnitude, a exemplo da greve dos ferroviários na França, em 1995. Paralisação de grande amplitu- de envolvendo assalariados, desempregados e aposentados somente obteve êxito porque foi desencadeada pela organização dos "cheminots" (ferroviários) e contou com o apoio da maioria absoluta da população (Meyer, 2001).

E no Brasil? No mesmo ano em que os ferroviários paralisaram a França, o governo de Fernando Henrique Cardoso, em nome da estabilidade monetária e da ortodoxia do Plano Real, conseguiu impor uma derrota política aos petroleiros em greve (Lobo e Stotz, 1998). Poder-seia ver ali o início de um prolongado refluxo do movimento sindical. De fato, aquela greve aparece como um "ponto de viragem" de um movimento que refluiu para o interior das empresas. Apenas no final da década de 90, assistimos à primeira greve dos metalúrgicos de São Paulo e do $\mathrm{ABC}$, demonstrando também que a resistência operava por caminhos não visíveis. ${ }^{13}$

Porém, não estaria o sindicalismo brasileiro excessivamente amarrado ao atrelamento imposto pelo Estado ou, ainda, dominado por uma tradição corporativista para vislumbrar novos horizontes, abertos a reivindicações de cunho social e político? Isso depende. Se na sociedade a única previsão realista é a da luta, as circunstâncias sempre podem favorecer a emergência de lutas mais amplas, dependendo, em boa medida, da capacidade das lideranças saberem aproveitar as circunstâncias. Um exemplo disso foi a ocupação, em 1992, das dependências do Hospital Antonio Pedro pelos metalúrgicos de Niterói, em protesto contra o fechamento da emergência e a ameaça da criação de dupla porta de entrada para pacientes dos setores privado e público. O hospital, vinculado à Universidade Federal Fluminense, é uma instituição de referência terciária de toda a região litorânea do Estado do Rio de Janeiro. ${ }^{14}$ Foi um evento isolado que trazia, porém, do ponto de vista prático, um certo enfrentamento do corporativismo e que mostrou, de modo concreto, o ponto de vista operário sobre interesses mais amplos do que os de uma categoria específica.

Recentemente, jornal de grande circulação no meio empresarial noticiou, com destaque, o fracasso da privatização do setor de saneamento básico na Bahia. A mobilização e a luta envolveram, de um lado, a Igreja católica e o sindicato de trabalhadores e, de outro, prefeitos sob a liderança de Antonio Carlos Magalhães e a multinacional inglesa Thames Water. No processo de mobilização popular contra a privatização da Empresa Baiana de Saneamento (Embasa), a maior empresa de saneamento do Nordeste, foram recolhidas assinaturas para viabilizar projetos de lei de iniciativa popular. Em Salva- 
dor, o projeto entregue à Câmara dos Vereadores contava com 92 mil assinaturas. Com a suspensão da privatização da Embasa, o BNDES passou a não ter mais nenhum processo de venda das 27 empresas estaduais do setor ( $\mathrm{Va}$ lor, 15 a 17/03/2002).

O que esses eventos indicam é que a participação política dos segmentos mais organizados dos trabalhadores urbanos pode reforçar as reivindicações e aspirações da maioria dos segmentos - mais pobres e vulneráveis - das classes trabalhadoras pelo direito à saúde, expresso por política públicas de promoção das condições de vida, mas igualmente por cuidados aos problemas de saúde, quer dizer, oferta adequada de serviços públicos de qualidade. Trata-se de uma verdadeira agenda política a ser assumida pelo movimento sindical e pelos que se consideram herdeiros do movimento da reforma sanitária, dentro e fora de governos populares. O desafio maior do movimento organizado dos trabalhadores consiste em transformar movimentos e lutas locais ou mesmo regionais em movimentos políticos, sob os termos mais amplos da seguridade (ou proteção) social. Em última análise, é o próprio perfil das políticas públicas e sua relação com o regime político democrático que está em pauta nesta perspectiva.

\section{NOTAS}

1. Os Cadernos foram publicados inicialmente pela Editora Civilização Brasileira, em 1968, sob os títulos de Maquiavel, a Política e o Estado Moderno e Concepção Dialética da História.

2. A primeira edição da obra na França data de 1977.

3. A manipulação clientelística dos eleitores, através da falsificação dos benefícios previdenciários, foi praticada com certa freqüência pelos partidos oficialmente permitidos pela ditadura militar, principalmente nas cidades do interior do país.

4. Uma análise do movimento sob a perspectiva dessas forças sociais encontra-se em Escorel (1998).

5. Nesse ano, surge o Cebes - Centro Brasileiro de Saúde Coletiva. Ao lado do Cebes, grupos acadêmicos do Instituto de Medicina Social, da UERJ, da Escola Nacional de Saúde Pública, da Fiocruz e dos departamentos de medicina preventiva e comunitária, que então se organizavam nas universidades em São Paulo e Bahia, iniciaram, em 1977. uma articulação nacional com vistas a impulsionar programas de residência em medicina preventiva, social ou de saúde pública. O objetivo era formar quadros dentro da nova concepção delineada na fundação do Cebes. Tais iniciativas convergiram para a fundação da Abrasco - Associação Brasileira de Pós-Graduação em Saúde Coletiva, em 1979, uma entidade organizada para reunir tanto docentes quanto profissionais de saúde com pós-graduação lato sensu.

6. É interessante que a autora inscreva, nessa tendência, o movimento de reforma psiquiátrica.

7. É importante registrar, nesse sentido, a tradução de textos oriundos da esquerda marxista nos Estados Unidos e em países da América Latina, publicados em instrumentos para a formação de sanitaristas, a exemplo dos Textos de Apoio PEC-ENSP/Abrasco (Ciências Sociais, Epidemiologia, Planejamento).
8. Eis como isso acontece: o SUS oferece, sob contrato, leitos e serviços a planos e seguros de saúde ("dupla porta"); usuários do sistema privado utilizam a rede pública, especialmente para itens de alto custo (medicamentos para Aids, clínicas especializadas) e emergência, muitas vezes graças às suas influências sobre os corpos médicos das unidades de saúde. Porém, não se pode deixar de observar que, quanto ao atendimento ambulatorial em geral, a massa de associados aos planos e seguros privados "desonera" a rede pública de grandes contingentes de usuários.

9. Outra dimensão é a da desigualdade regional na oferta pública de serviços. Os serviços de alta complexidade, por exemplo, concentramse na região Sudeste, em especial na cidade de São Paulo.

10. A importância das ações básicas de saúde é inegável diante do perfil das causas de mortalidade proporcional da população brasileira, nas quais as mortes por doenças evitáveis ainda têm um peso considerável. Porém, é impossível esquecer que, nos padrões vigentes na sociedade brasileira, os mais pobres morrem mais por todas as causas.

11. Para Navarro (1983), a medicina reproduz a ideologia capitalista (liberalismo e individualismo) ao atribuir a causa das enfermidades a fatores individuais, ao mesmo tempo em que participa na alienação característica da sociedade capitalista ao transformar os cidadãos em usuários, em receptores de cuidado, sem controle sobre a natureza e a definição de sua própria saúde.

12. A fragmentação do mundo do trabalho é uma resultante do processo imediato da reestruturação industrial, isto é, da tendência à "focalização" das empresas em seus negócios ou atividades principais. A natureza econômica desse processo e sua justificativa na ideologia da livre empresa tornam mais difícil a resistência coletiva, na medida em que o questionamento do direito de propriedade não integra a cultura e a tradição de luta do operariado, principalmente em países como o Brasil.

13. Numa greve considerada legal pela Justiça do Trabalho, os metalúrgicos das montadoras e autopeças do $\mathrm{ABC}$ conquistaram, em $2000,10 \%$ de aumento salarial. A ameaça do desemprego deixou de ter eficácia naquele momento por conta da situação do mercado de trabalho no setor, indicando, provavelmente, o fim de uma fase de acumulação de capital. Nas palavras de Maria Cristina Cacciamali, professora de economia do trabalho da USP: "as empresas estão enxutas, não têm mais como cortar custos e, se demitirem, terão de substituir pessoal e treinar o novo empregado" (Folha de S.Paulo, 18/11/2000, B-6).

14. Informações prestadas por Aluísio Gomes da Silva Junior, em 07 de julho de 2002 .

\section{REFERÊNCIAS BIBLIOGRÁFICAS}

ANDRADE, R. de C. Política social e normalização institucional no Brasil. In: MAIRA, L. et al. América Latina: novas estratégias de dominação. Petrópolis: Vozes; São Paulo: Cedec, 1982.

AURELIANO, L.; DRAIBE, S.M. A especificidade do "Welfare State" brasileiro. In: MPAS/CEPAL. A política social em tempo de crise: articulação institucional e descentralização. Brasília: Cepal, 1989.

BANCO MUNDIAL. Relatório sobre o desenvolvimento mundial 1993 - investindo em saúde. Rio de Janeiro: Fundação Getúlio Vargas, 1993.

BRUNHOFF, S. de. Estado e capital: uma análise da política econômica. Rio de Janeiro: Forense Universitária, 1985.

CNS - CONSELHO NACIONAL DE SAÚDE. Desenvolvimento do sistema único de saúde no Brasil: avanços, desafios e reafirmação de princípios e diretrizes. Brasília: ago. 2002 (Versão preliminar). 
ESCOREL, S. Reviravolta na saúde: origem e articulação do movimento sanitário. Rio de Janeiro: Editora Fiocruz, 1998.

FAVARET FILHO, P.; OLIVEIRA, P.J. de. A universalização excludente: reflexões sobre as tendências do sistema de saúde. Rio de Janeiro: UFRJ/IEI, 1989.

FLEURY, S.M.T. Estado sem cidadãos: seguridade social na América Latina. Rio de Janeiro: Editora da Fiocruz, 1994.

. A questão democrática na Saúde. In: FLEURY, S.M.T. (Org.). Saúde e democracia: a luta do Cebes. São Paulo: Lemos Editora, 1997.

IBGE. Pesquisa Nacional por Amostra de Domicílios - PNAD. Rio de Janeiro: 1998.

LOBATO, L. de V.C. Reforma sanitária e reorganização do sistema de serviços de saúde: efeitos sobre a cobertura e a utilização dos serviços. 2000. Tese (Doutorado). Escola Nacional de Saúde Pública, Rio de Janeiro, 2000.

LOBO, E.M.L.; STOTZ, E.N. Tira o retrato do velho, põe o retrato do velho. O movimento sindical contemporâneo e o fim da era Vargas: uma avaliação Latin American Labor "Occasional Paper", 24. Miami, 1998.

MATTOSO, J.E.L. O novo e inseguro mundo do trabalho nos países avançados. In: OLIVEIRA, C.A.B. de. et al. (Orgs.). O mundo do trabalho. São Paulo: Ed. Página Aberta Ltda., 1994.

MEYER, V.A. Reação: articulação e organização internacional dos trabalhadores ante a globalização - um fenômeno emergente. Salvador: Casa da Qualidade, 2001.

MISOCZKY, M.C. A agenda para reformas do Banco Mundial e a política de saúde: algumas notas para reflexão. Saúde em debate. Londrina: Centro Brasileiro de Estudos de Saúde, 47, jun. 1995, p.4-7.

NAVARRO, V. Classe social, poder político e o Estado e suas implicações na medicina. In: Programa de Educação Continuada da Escola Nacional de Saúde Pública/Associação Brasileira de Pós-
Graduação em Saúde Coletiva. Textos de Apoio - Ciências Sociais 1. Rio de Janeiro: 1983.

Produção e Estado de Bem-Estar. O contexto político das reformas. Lua Nova. São Paulo: n.28/29, 1993, p.157-199.

OFFE, C. Capitalismo desorganizado: transformações contemporâneas do trabalho da política. São Paulo: Brasiliense, 1994.

OLIVEIRA, J.A. Reforma e reformismo: para uma teoria política da reforma sanitária (ou reflexões sobre a reforma sanitária de uma perspectiva popular). In: COSTA et al. (Orgs.). Demandas populares, políticas públicas e saúde. Petrópolis: Vozes; Rio de Janeiro: Abrasco, v.I, 1989.

OLIVEIRA, J.A; FLEURY, S.M. (Im) previdência social: 60 anos de história no Brasil. Petrópolis: Vozes, 1986.

STOTZ, E.N.; CRUZ NETO, O. Processo de trabalho e saúde - o caso dos trabalhadores em curtume. Demandas populares, politicas públicas e saúde. Petrópolis: Vozes; Rio de Janeiro: Abrasco, v. II, 1989.

VAlla, V.V. Reflexões desenvolvidas a partir do Projeto de Pesquisa: Educação, Saúde e Cidadania. Rio de Janeiro: Escola Nacional de Saúde Pública, 1988 (Relatório Final apresentado à Finep).

VALLA, V.V.; STOTZ, E.N. Educação, saúde e cidadania. Petrópolis: Vozes, 1994.

VALOR. Pressão da Igreja barra privatização baiana. São Paulo, 15, 16 e 17 mar. 2002. Caderno A, p.12.

VIANNA, M.T.L.W. A americanização (perversa) da seguridade social no Brasil; estratégias de bem-estar e políticas públicas. Rio de Janeiro: Ucam; Revan, 1998.

Eduardo Navarro Stotz: Pesquisador da Escola Nacional de Saúde Pública, Fiocruz (stotz@alternex.com.br). 